\title{
Oral Cavity Assessment among Ventilated Children at Pediatric Intensive Care Unit
}

\author{
Adel Amin Ebrahim ${ }^{1}$, Eman Sayed Ahmmed ${ }^{2}$, Azza Ahmed Eltayeb ${ }^{3}$ \& Etemad Hassien Sayed ${ }^{4}$ \\ 1. Nursing Specialist at Authority of Dhamar General Hospital ,Yemen \\ 2. Professor of Pediatric Nursing, Faculty of Nursing, Assiut University, Egypt. \\ 3. Professor of Pediatrics, Faculty of Medicine, Assiut University, Egypt. \\ 4. Lecturer of Pediatric Nursing, Faculty of Nursing, Assiut University, Egypt.
}

\begin{abstract}
:
Mouth care has a crucial role in preventing mucositis in pediatric patients who admitted to pediatric intensive care unit and undergoing mechanical ventilation. Aim: was aimed to assess oral cavity for children undergoing mechanical ventilated at Pediatric Intensive Care Unit. Subjects and method: A descriptive research design was used. The study were included 60 children (>6 years age) admitted at PICU undergoing mechanical ventilation. Tools: Data collection tools included: Socio-demographic characteristic and clinical data structured questionnaire, and oral cavity assessment tool. Results: It was found that most frequently occurring risk factors of mucositis among studied children were fever, drugs and malnutrition $(66.7 \%$ \& $23.3 \%$ \& $20.0 \%)$ respectively and $63.3 \%$ of the studied children had moderate oral mucositis while quarter of them had severe oral mucositis. Conclusion: Children undergoing mechanical ventilation at the pediatric intensive care unit had moderate and severe oral mucositis. Recommendations: The use of an oral cavity assessment instrument is suggested for the early detection of oral infection for every patient and instruct nurses for using proper mouth care.
\end{abstract}

\section{Keywords: Oral cavity assessment, Children, Mechanical Ventilation \& Pediatric intensive care unit.}

\section{Introduction:}

Oral mouth care although a technical challenge to be performed for intubated patients, is critical to be done for the overall health, safety, and comfort of the patient. Oral hygiene is vitally important because oral health is directly related to systemic health. Poor oral health results in plaque buildup and inflammation of the gingiva (Saensom et al,.2016 \& Gupta et al., 2016).

Good oral health is a state of being free from oral disease, pain, or infection that limits an individual's ability to eat, speak and socialize. Periodontitis is one of the most common diseases worldwide, which is closely linked with poor oral hygiene and major noncommunicable diseases (Peres et al., 2019). Oral health and oral hygiene should be recognized as essential components of a healthy lifestyle; however, it has been given rare attention. The oral health of hospitalized patients has been found to decline worldwide, with an increase in the amount of dental plaque and gingival infection which occurred within 7-20 days of hospitalization (Dagnew et al,. 2020).

Oral mucositis (OM) commonly causes severe pain and discomfort that can affect the oral intake as well as the child's ability to communicate and sleep, and, therefore, a significant impairment in a child's quality of life (Guimarães et al., 2021). Oral mucositis affects the progression of the treatment regimen and utilization of health care services. OM is a source of extra morbidity, which has increased health care costs and affected a patient's quality of life. There are a limited number of studies focused on the pediatric population (Damascena, et al., 2020).

Providing oral care hygiene for children in the intensive care unit and protecting oral mucosa are important in the promotion of healthy nutrition, comfort, and increasing patients' quality of life, as well as preventing infections that might develop in the oropharynx and respiratory tract (Düzkaya et al., 2017). Although pediatric patients in intensive care require frequent oral care, this is commonly overlooked by nurses (Anggraeni et al., 2020).

\section{Significance of study:}

Oral hygiene research have largely been undertaken in pediatric patients detected that mucosal integrity deteriorated and function loss occurred at a medium level in $62.6 \%$ of children after endotracheal tube intubation (Mohammed \& Hassan, 2015).

In Egypt, there has been no clear evidence identified oral cavity assessment for children undergoing mechanical ventilated. Therefore, it can be argued that the current study will add to the body of knowledge. By identifying oral infection among ventilated children, this information can be used to help in service planning and improve to deliver evidence based practice among pediatric intensive care unit patients. 
Aim of study

Was aimed to: This study aims to assess oral cavity for children undergoing mechanical ventilation at Pediatric Intensive Care Unit.

\section{Research question:}

The following research question was designed to achieve the study's aims:

What is the oral condition of ventilated children as assessed by the researcher at pediatric intensive care units?

\section{Subjects and Method:}

Research design: A descriptive research design was used in the study.

Study setting: This study was conducted at the pediatric Intensive Care Unit (PICU) of Assuit University Children Hospital.

Study subjects: The study included 60 children $(>6$ years age) were admitted to PICU and needed mechanical ventilation who meet inclusion criteria.

The inclusion criteria are:

- Children who were intubated and connected to mechanical ventilation (MV) for $>48 \mathrm{~h}$.

- Age > 6 years. ( 6-12. 12-18years school and adolescent ).

\section{Tools of data collection:}

The present study data was gathered using the following tools:

Tool I: Sociodemographic and clinical characteristics structured questionnaire: this tool was developed by the researcher and consists of two parts:

\section{Part 1: Sociodemographic Characteristics:}

Sociodemographic characteristics that includes: age, gender, residence and date of admission.

\section{Part 2: Clinical characteristics:}

a.Diagnosis, neuromuscular-blocking-drugs, duration of ventilated children, mode of ventilation, and duration in pediatric intensive care unit stay.

b.Feeding types: Enteral feeding, parenteral feeding and nasogastric tube feeding.

Tool II: Oral Cavity Assessment Tool:

Oral cavity assessment tool includes: mucous membranes, saliva, tongue, lips, gums, teeth, ability to maintain nutrition (normal diet, soft diet and fluids only or nil by mouth), analgesic requirements, and evidence of infection. This tool was developed by (Harris et al., 2008). It was modified by the researcher by removing $\mathbf{4}$ items (voice, swallow, taste, and self-care assessment because of intubation). Each item has a score range from 1 to 3 . The total score was 27. Each category is treated as a subscale, and the total score is a sum of 9 subscales. The total scores range from 9 to 27 . The score was ranked as follows 9-16 denotes mild alteration of mouth, 17-22 denotes moderate alteration, and 23-27 denotes severe alteration of mouth.

Method:

Administrative process: An official permission was obtained from the faculty of Nursing and was submitted to the responsible authorities of selected setting for permission to carry out the study.

\section{Ethical considerations:}

a) There was no risk for study subjects during the application of the research.

b) Oral consent was obtained from parents who were willing to participate in the study, after explaining the purpose of the study.

c) Parents have the right to refuse to participate and/or withdraw from the study at any time

d) Confidentiality and privacy was taken into consideration regarding the data collection of the study sample

Study tools were developed \&modified based on review of related literature by using Tool (I, II).

Validity was done for all tools by five experts from faculty members in the nursing and medical field of Assiut University. Three of them were from pediatric nursing and two from pediatrics were from different academic categories, i.e., professor and assistant professors, to confirm the accuracy and relevance of the information and tools. The content validity index (CVI) was 0.8 .

The internal consistency of reliability was carried out using the Cronbach alpha coefficient test to oral cavity assessment tool (OCAT). It was found to be $(\mathrm{r}=0.92)$.

Pilot study was done on $10 \%$ of study sample from the previously mentioned setting to test the clarity, feasibility and applicability of the tool. It was modified accordingly and make ready for use. The data obtained was excluded from the study sample.

The present study's data was gathered over a sixmonth period, from December 2018 till the end of May 2019, 3 days per week $\backslash 4$ hours from 9 am to 1 pm. The interviewer selected children who fulfilled the criteria from the previously mentioned setting. Each participant was individually assessed in PICU in order to collect the data. Then the researcher observed and records the answers in the oral cavity assessment tools, the tools were filled and completed in one session. The average time taken for completing tools was around 20-30 minutes.

Statistical design:

Collected data were verified prior to computerized data entry and analysis by using statistical software package for social sciences (SPSS-20). Data were presented using descriptive statistics in the form categorical variables were described by frequencies and percentages, while continuous variables described by mean and standard deviation. 


\section{Results:-}

Table (1): Distribution of children characteristics undergoing mechanical ventilation pediatric intensive care unit

\begin{tabular}{|c|c|c|}
\hline \multirow{2}{*}{ Variables } & \multicolumn{2}{|c|}{ Ventilated Children (n= 60) } \\
\cline { 2 - 3 } & No. & \multicolumn{1}{c|}{} \\
\hline Age: (years) & & $\mathbf{6 1 . 7}$ \\
\hline $6-<12$ & 37 & 38.3 \\
\hline $12-18$ & 23 & $\mathbf{1 0 . 4 3} \pm \mathbf{3 . 1 3}$ \\
\hline Mean \pm SD & \multicolumn{2}{|c|}{} \\
\hline Sex: & 35 & $\mathbf{5 8 . 3}$ \\
\hline Male & 25 & 41.7 \\
\hline Female & & $\mathbf{5 3 . 3}$ \\
\hline Residence: & 32 & 46.7 \\
\hline Urban & 28 & \\
\hline Rural & & \\
\hline
\end{tabular}

Table (2): Distribution of children undergoing mechanical ventilation regarding diagnosis at pediatric intensive care unit

\begin{tabular}{|l|c|c|}
\hline \multicolumn{1}{c|}{ Diagnosis } & \multicolumn{2}{c|}{ Ventilated Children (n= 60) } \\
\cline { 2 - 3 } \multicolumn{1}{c|}{} & No. & $\mathbf{1 8 . 3}$ \\
\hline Bronchopneumonia & 11 & $\mathbf{1 3 . 3}$ \\
\hline Renal failure & 7 & $\mathbf{1 1 . 7}$ \\
\hline Nephrotic syndrome & 6 & 10.0 \\
\hline Heart failure & 4 & 6.7 \\
\hline Diabetes Mellitus(DM) & 2 & 3.3 \\
\hline Chronic kidney disease(CKD) & 3 & 5.0 \\
\hline Encephalitis & 3 & 5.0 \\
\hline Guillain barre syndrome & 3 & 5.0 \\
\hline Hepatitis & 5 & 8.3 \\
\hline Meningitis & 2 & 3.3 \\
\hline Status epilepticus & 3 & 5.0 \\
\hline Poisoning & 6 & 10.0 \\
\hline Others\# & 6 & \\
\hline
\end{tabular}

More than one disease were allowed

\#Others include; Gastrointestinal, Hemolytic uremic, Pulmonary edema, Brain abscess, fallot tetralogy and

Dilated cardiomyopathy.

Table (3): Distribution of children undergoing mechanical ventilation regarding clinical data at pediatric intensive care unit

\begin{tabular}{|c|c|c|}
\hline \multirow{2}{*}{ Variable } & \multicolumn{2}{|c|}{ Ventilated Children $(n=60)$} \\
\hline & No. & $\%$ \\
\hline \multicolumn{3}{|l|}{ Nutrition type: } \\
\hline Parenteral feeding & 6 & 10.0 \\
\hline Nasogastric tube (NGT) feeding & 54 & 90.0 \\
\hline \multicolumn{3}{|l|}{ Neuromuscular-blocking-drugs: } \\
\hline Yes & 12 & 20.0 \\
\hline No & 48 & 80.0 \\
\hline \multicolumn{3}{|l|}{ Type of Endotracheal tube (ETT): } \\
\hline Cuffed & 32 & 53.3 \\
\hline Uncuffed & 28 & 46.7 \\
\hline \multicolumn{3}{|l|}{ Mode of ventilation: } \\
\hline SIMV & 46 & 76.7 \\
\hline PSV & 14 & 23.3 \\
\hline \multicolumn{3}{|l|}{ Tube size: } \\
\hline Mean \pm SD (Range) & \multicolumn{2}{|c|}{$5.84 \pm 0.74(5-7)$} \\
\hline Less than $6 \mathrm{~mm}$ & 40 & 66.7 \\
\hline More than $6 \mathrm{~mm}$ & 20 & 33.3 \\
\hline
\end{tabular}




\begin{tabular}{|c|c|c|}
\hline \multirow{2}{*}{ Variable } & \multicolumn{2}{|c|}{ Ventilated Children $(n=60)$} \\
\hline & No. & $\%$ \\
\hline \multicolumn{3}{|l|}{ Duration of ventilation: } \\
\hline Mean \pm SD (Range) & \multicolumn{2}{|c|}{$9.41 \pm 3.64(6-21)$} \\
\hline $5-10$ days & 45 & 75.0 \\
\hline$>10$ days & 15 & 25.0 \\
\hline \multicolumn{3}{|l|}{ Duration of PICU stay: } \\
\hline Mean \pm SD (Range) & \multicolumn{2}{|c|}{$11.24 \pm 3.89(6-25)$} \\
\hline 5-10 days & 31 & 51.7 \\
\hline$>10$ days & 29 & 48.3 \\
\hline
\end{tabular}

SIMV: synchronized intermittent mandatory ventilation

PSV: pressure support ventilation

Table (4): Distribution of children undergoing mechanical ventilation regarding risk factor for mucositis at pediatric intensive care unit

\begin{tabular}{|l|c|c|}
\hline \multirow{2}{*}{ Risk factors for mucositis } & \multicolumn{2}{c|}{ Ventilated Children $(\mathbf{n}=\mathbf{6 0})$} \\
\cline { 2 - 3 } & No. & $\mathbf{\%}$ \\
\hline Drugs & 14 & $\mathbf{2 3 . 3}$ \\
\hline Fever & 40 & $\mathbf{6 6 . 7}$ \\
\hline Malnutrition & 12 & $\mathbf{2 0 . 0}$ \\
\hline Oxygen therapy(O2) & 4 & 6.7 \\
\hline Immunodeficiency & 5 & 8.3 \\
\hline Convulsions & 3 & 5.0 \\
\hline
\end{tabular}

*more than answer.

$*$ drugs $=$ steroid,immune supp, atropin.

Table (5): Mean oral cavity assessment score among ventilated children at pediatric intensive care unit

\begin{tabular}{|l|c|c|}
\hline Oral cavity assessment score & Total score & Ventilated Children $(\mathbf{n}=\mathbf{6 0})$ \\
\hline Mean \pm SD & \multirow{2}{*}{27} & $\mathbf{2 0 . 4 7 \pm 2 . 7 5}$ \\
\cline { 1 - 1 } Range & & $15.0-25.0$ \\
\hline
\end{tabular}

Table (6): levels of oral cavity assessment among ventilated children at pediatric intensive care unit

\begin{tabular}{|l|c|c|}
\hline \multirow{2}{*}{ Levels of oral cavity assessment } & \multicolumn{2}{|c|}{ Ventilated Children $(\mathbf{n}=\mathbf{6 0})$} \\
\cline { 2 - 3 } & No. & \% \\
\hline Normal mucositis & 0 & 0.0 \\
\hline Mild mucositis & 8 & 13.3 \\
\hline Moderate mucositis & 38 & $\mathbf{6 3 . 3}$ \\
\hline Severe mucositis & 14 & 23.4 \\
\hline
\end{tabular}

Table (7): Distribution of children undergoing mechanical ventilation regarding sub items of oral cavity assessment tool (OCAT) at pediatric intensive care unit.

\begin{tabular}{|l|c|c|}
\hline \multicolumn{1}{|c|}{ Oral cavity condition } & \multicolumn{2}{c|}{ Ventilated Children (n= 60) } \\
\cline { 2 - 3 } & No. & \% \\
\hline Mucous membranes & & 3.3 \\
\hline Pink and moist & 2 & $\mathbf{6 6 . 7}$ \\
\hline Red or coated & 40 & 30.0 \\
\hline Ulcerated+/- bleeding & 18 & \\
\hline Tongue & & 6.7 \\
\hline Pink and moist & 4 & $\mathbf{8 0 . 0}$ \\
\hline Coated or shiny +/- bleeding & 48 & 13.3 \\
\hline Ulcerated+/- bleeding & 8 & \\
\hline Lips & & 0.0 \\
\hline Smooth, pink and moist & 0 & $\mathbf{6 3 . 3}$ \\
\hline Dry/ cracked & 38 & 36.7 \\
\hline Bleeding/ ulcerated & 22 & \\
\hline
\end{tabular}




\begin{tabular}{|c|c|c|}
\hline \multirow{2}{*}{ Oral cavity condition } & \multicolumn{2}{|c|}{ Ventilated Children $(n=60)$} \\
\hline & No. & $\%$ \\
\hline \multicolumn{3}{|l|}{ Saliva } \\
\hline Watery & 0 & 0.0 \\
\hline Thick or ropy & 34 & $\mathbf{5 6 . 7}$ \\
\hline Absent & 26 & 43.3 \\
\hline \multicolumn{3}{|l|}{ Gums } \\
\hline Pink and firm & 8 & 13.3 \\
\hline Oedamatous $+/$ - redness & 48 & $\mathbf{8 0 . 0}$ \\
\hline Spontaneous bleeding & 4 & 6.7 \\
\hline \multicolumn{3}{|l|}{ Teeth } \\
\hline Clean, no debris & 24 & 40.0 \\
\hline Localized plaque, debris & 36 & $\mathbf{6 0 . 0}$ \\
\hline Generalized plaque and debris & 0 & 0.0 \\
\hline \multicolumn{3}{|l|}{ Ability to maintain nutrition } \\
\hline Normal diet & 0 & 0.0 \\
\hline Soft diet & 0 & 0.0 \\
\hline Fluids only or nil by mouth & 60 & 100.0 \\
\hline \multicolumn{3}{|l|}{ Analgesic requirements } \\
\hline None & 4 & 6.7 \\
\hline Topical analgesia & 2 & 3.3 \\
\hline Systemic analgesia & 54 & 90.0 \\
\hline \multicolumn{3}{|l|}{ Evidence of infection } \\
\hline No evidence of infection & 10 & 16.7 \\
\hline Some evidence visible & 42 & 70.0 \\
\hline Infection (viral/ fungal) & 8 & 13.3 \\
\hline
\end{tabular}

Table (1): Distribution of children characteristics undergoing mechanical ventilation pediatric intensive care unit. The table summarized that, the mean age of children were $10.43 \pm 3.13$ with $61.7 \%$ of them were less than 12 years. As regarding to sex, 58.3\% were male. Regarding residence $\mathbf{5 3 . 3 \%}$ of studied children lives in the urban area.

Table (2): Distribution of children undergoing mechanical ventilation regarding diagnosis at pediatric intensive care unit. It was found that the most common diagnosis in studied children were: bronchopneumonia $18.3 \%$, renal failure $13.3 \%$, and nephrotic syndrome $\mathbf{1 1 . 7 \%}$.

Table (3): Distribution of children undergoing mechanical ventilation regarding clinical data at pediatric intensive care unit. It was shown that majority $(\mathbf{9 0 . 0 \%})$ of studied children were taking their nutrition by nasogastric tube (NGT) the majority of studied children did not receive neuromuscular, blocking drugs. As regards type of endotracheal tube

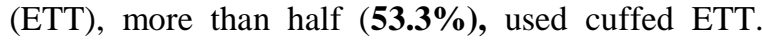
Also more than three quarters of studied children used mode of ventilation synchronized intermittent mandatory ventilation (SIMV). As regarding tube size, two thirds of studied children used tube less than 6 with mean size $\mathbf{5 . 8 4} \pm \mathbf{0 . 7 4}$. The mean duration of ventilation was $\mathbf{9 . 4 1} \pm \mathbf{3 . 6 4}$ among studied children. Also three quarters of them spent 5-10 days on mechanical ventilation. About more than half
(51.7\%) of studied children stayed 5-10 days in PICU.

Table (4): Distribution of children undergoing mechanical ventilation regarding risk factors for mucositis at pediatric intensive care unit. It was found that the most common risk factors in the study group were fever, drugs and malnutrition $(\mathbf{6 6 . 7 \%} \& \mathbf{2 3 . 3 \%}$ \& $\mathbf{2 0 . 0 \%}$ ) respectively.

Table (5): As noted mean score of oral cavity assessment among studied children. This table shows the mean score of OCAT in studied children were $20.47 \pm 2.75$.

Table (6): Presents level of oral cavity assessment among studied children. This table found that twothirds $(\mathbf{6 3 . 3 \%})$ of the studied children had moderate oral mucositis while one quarter $\mathbf{( 2 3 . 4 \% )}$ ) of them had severe oral mucositis.

Table (7): Distribution of children undergoing mechanical ventilation regarding sub items of oral cavity assessment tool (OCAT) at pediatric intensive care unit. This table illustrates that two thirds $(66.7 \%)$ of studied children had red or coated mucous membranes and majority of them had coated or shiny +bleeding tongue, whereas less than two thirds $(\mathbf{6 3 . 3 \%})$ of them had dry/cracked lips. In the regarding saliva more than half $\mathbf{5 6 . 7 \% )}$ of studied children had thick or ropy saliva and most of them had oedamatous $+/$ - redness gums. Also whereas less than two thirds $(\mathbf{6 0 . 0 \%})$ of studied children had localized plaque, debris regarding teeth. All studied 
children took fluids only or nil by mouth and majority of them needs systemic analgesia and more than two thirds $\mathbf{7 0 . 0 \%}$ ) of studied children had some evidence of infection.

\section{Discussion}

Standardized oral hygiene practices of infants and children in pediatric intensive care unit (PICU) contribute to improved oral and general health. Children undergoing intubation and mechanical ventilation in PICU are dependent on critical care nursing to perform daily mouth care to decrease infections, inflammatory and painful symptoms. Oral hygiene practice has positive significantly effects on children's well-being. The role of mouth health care in maintaining the well-being and health of patients in the intensive care unit settings is indisputable (Alsoda et al,. 2019).

The current study indicated that the mean age of studied children were $10.43 \pm 3.13$ with less than twothirds of them were from 6 to less than 12 years old and more than half of them were males. While more than half of the studied children lived in urban areas.

This was in agreement with the most recent study conducted by Gomaa et al., (2017) \& Abd El Fatah, et al., (2020) which showed the majority of children undergoing mechanical ventilation in PICU were males with a mean age of 10 years old and lived in urban areas.

Also, the current work revealed that the most common diagnosis among studied children were broncho-pneumonia. This finding is supported by AbdAllah et al., (2016) \& Abd El Fatah, et al., (2020) They reported that the most main diagnosis at PICU admission is respiratory diseases. On the other hand, it is incongruent with the study conducted by Ullman, et al., (2013) that clarified that the most common diagnosis of the studied children in PICU was respiratory failure. While Allen et al., (2018) found that the most common diagnosis of the studied children in PICU were encephalitis and meningitis. The current study mentioned that, the majority of studied children received nasogastric tube (NGT) feeding, and they did not receive neuromuscular blocking drugs. This finding was supported by a study conducted by Abo El-Ella et al., (2017) at Assiut university children's hospital that revealed the majority of children in PICU were on NGT feeding. From the viewpoint of the researcher, this finding is related to the fact that the majority of children in PICU are unconscious so NGT is used for purposes of nutritional and gastric decompression.

In the same context, this result is similar to previous studies reported by (Da Silva et al., 2010; Aelami et al., 2014; \& Düzkaya et al., 2017) who documented that, majority of studied children did not receive neuromuscular blocking drugs.

Considering the type of the endotracheal tube, this study revealed that, more than half of them were cuffed endotracheal tube. This result was in agreement with the previous study by Mohammed \& Hassan, (2015) who documented that, majority of studied children used cuffed endotracheal tube. While this result was disagreement with the previous study by Kusahara et al., (2012) stated that more than half of the studied children used uncuffed endotracheal tube. From the viewpoint of the researcher, this result is due to that uncuffed endotracheal tube was not available in enough amounts in PICU during data collected.

The present study showed that three fourths of studied children used mode of ventilation synchronized intermittent mandatory ventilation (SIMV). This result is similar to previous studies reported by (Aelami, et al., 2014; Abutbul et al., 2014 \& Abd El Fatah et al., 2020) who documented that, majority of studied children used mode of ventilation synchronized intermittent mandatory ventilation (SIMV). The viewpoint of the researcher about the reason for using SIMV mode in the majority of patients in PICU is related to the fact that SIMV has been the conventional mode of ventilation in many intensive care units (ICUs) worldwide for decades to prepare pediatric patients for weaning because this mode is considered also a mode of weaning.

In addition, in SIMV, the ICU physician sets the respiratory rate, tidal volume and pressure support levels, positive end-expiratory pressure (PEEP), and fractional inspired concentration of oxygen ( $\mathrm{FiO} 2)$. Once set, the settings are static until changed again by the physician on the basis of changing monitored parameters such as respiratory rate, pulse oximetry, end-tidal $\mathrm{CO} 2$, or intermittent arterial blood gas measurements.

The current study found that the mean duration of ventilation of the studied children were $9.41 \pm 3.64$ days and most of them spent from 5 to 10 days on mechanical ventilation.

This finding was similar to a previous study by Gomaa et al., (2017) \& Abd El Fatah et al., (2020) who found that the mean duration of ventilation of the studied children were $8.88 \pm 4.82$ days and most of them spent from 4 to 10 days on mechanical ventilation.

Also, Kusahara et al., (2012) reported that the mean duration of ventilation of the studied children were $9.48 \pm 6.89$ days. However, the current result disagrees with Düzkaya et al., (2017) who reported that the mean duration of ventilation of the studied children were $5.43 \pm 3.69$ days. 
The present study indicated that the mean duration of PICU stay among the studied children were 11.24 \pm 3.89-days with more than half of them stayed from 5 to 10 days in PICU.

This result is consistent with a previous study by AbdAllah et al., (2016) \& Düzkaya et al., (2017) who found that the mean duration of PICU stay among the studied children were $11.56 \pm 1.45$ days, and most of them stayed from 10 to 12 days in PICU. In this respect, a previous study conducted by Kusahara et al., (2012) reported that the mean duration of PICU stays among the studied children were $15.08 \pm 23.06$ days

Concerning the risk factors, the current work concluded that the most common risk factors among studied children were fever, drugs, and malnutrition.

This was in accordance with previous studies reported by (Düzkaya, et al., 2017 \& Abo El-Ella et al., 2017) who revealed that the most common risk factors among the studied children were fever and malnutrition.

As regards oral cavity assessment the present study as noted that the mean score of oral cavity assessment in the studied children was $20.47 \pm 2.75$ with two thirds of the studied children had moderate oral mucositis and one quarter of them had severe oral mucositis. This finding similar to previous studies done by (Ames et al., 2011; Ahmed, 2013 and Mohammed \& Hassan, 2015; \& Anggraeni et al., 2020; Afrasiabifar et al., 2020) who found that majority of studied children had moderate oral mucositis. From the viewpoint of the researcher, this result is due to pediatric patients on mechanical ventilation and did not receive frequent oral care.

When studying the subscales of oral cavity assessment regarding PICU under mechanical ventilation, two thirds of studied children had red or coated mucous membranes and majority of them had coated or shiny +bleeding tongue, whereas less than two thirds of them had dry/cracked lips. In the regarding saliva more than half of studied children had thick or ropy saliva and most of them had oedamatous +/- redness gums. Also whereas less than two thirds of studied children had localized plaque, debris regarding teeth. All studied children took fluids only or nil by mouth and majority of them needs systemic analgesia and more than two thirds of studied children had some evidence of infection. These findings are in agreement with (Yurdanur, \& Yagmur, 2016; Moustafa et al., 2016 \& Kusiak et al., 2020) who reported that most of the studied children that majority of studied children had red or coated mucous membranes and coated or shiny +bleeding tongue. About two thirds of them had dry/cracked lips. Regarding saliva more than half of studied children had thick or ropy saliva and majority of them had oedamatous +/- redness gums. As regards teeth, it can be noted that two thirds of studied children had localized plaque, debris regarding teeth. From the viewpoint of the researcher, this result could be due to defected immunity system, not taking food from mouth, dryness, giving un-moisturized oxygen via facemask the damage by endotracheal tube, bad mouth hygiene and bad perfusion.

The current study revealed that all of the studied children were on fluids only or nil by mouth. This finding was supported by Blevins, (2011) \& Afrasiabifar et al., (2020) who documented that entire patients in PICU were on fluids only or nil by mouth. From the viewpoint of the researcher, this finding is due to that most of children in the PICU were unconscious and unable to control swallowing so any food or fluid by mouth might cause aspiration, pneumonia, and death

Regarding evidence of infection, the current work concluded that, more than two thirds of studied children had some evidence of infection. These findings are consistent with previous studies conducted by (Kusahara et al., 2012 \& Moustafa et al., 2016) who reported that of studied children had some evidence of infection. From the viewpoint of the researcher, this result might be related to access of bacteria to respiratory tract due to endotracheal tube becomes easier especially for patients in PICU who are associated with ventilation.

\section{Conclusion: Based on the current study it was concluded that:}

Children undergoing mechanical ventilation at the pediatric intensive care unit had moderate and severe oral mucositis and the most common risk factors in oral mucositis were fever, drugs, and malnutrition.

\section{Recommendations}

Based on the current study findings, the following recommendations are suggested

1- Equipment for oral hygiene should be accessible at pediatric intensive care units.

2- Children undergoing mechanical ventilation should be cared by qualified nurses to reduce the incidence of mucositis associated with the ventilator. Use a soft and small toothbrush to clean patients' teeth, tongue and gums at least twice a day to remove plaque teeth.

3- Educational program regarding the oral assessment of children undergoing mechanical ventilation in PICU is essential for nurses to improve their knowledge and practices.

4- The use of an oral cavity assessment instrument is suggested for the early detection of oral infection for every patient and instruct nurses for using proper mouth care. 


\section{References}

- Abd El Fatah, K., Abdul Rahman, L., \& Agaarib, F. (2020): Assist Control Ventilation Versus Synchronized Mode Intermittent Mandatory Ventilation in Pediatric Intensive Care Unit. The Egyptian Journal of Hospital Medicine, 81(4), 19031909.

- AbdAllah., B., Zeitoun., D., \& Fattah, A. (2016): Adherence to standard admission and discharge criteria and its association with outcome of pediatric intensive care unit cases in Al-Ahrar Hospital Zagazig. Egyptian Pediatric Association Gazette, 64(3), 111-119

- Abo El-Ella, M., \& El-Deen, M. (2017): Risk Factors and Nursing Interventions for VentilatorAssociated Pneumonia in Pediatric Intensive Care Unit at Assiut University Children Hospital. Assiut Scientific Nursing Journal, 5(11), 16-25.

- Abutbul, A., Sviri, S., Zbedat, V., Linton, M., \& van Heerden, V. (2014): A prospective comparison of the efficacy and safety of fully closed-loop control ventilation (Intellivent-ASV) with conventional ASV and SIMV modes. Southern African Journal of Critical Care, 30(1), 28-32.

- Aelami, MH Lotfi, \& M Zingg, W. (2014): Ventilator-associated pneumonia in neonates, infants and children. Antimicrobial Resistance and Infection Control, 3(30), 1-10

- Afrasiabifar, A., Mosavi, A., \& Mozaffari, N. (2020): Oral Mucositis: Examining the Combined Solution of Grape Vinegar and Rose Water Versus Chlorhexidine Mouthwash. Clinical Journal of Oncology Nursing, 24(6), 71-78.

- Ahmed, M. (2013): The effect of olive leaf extract in decreasing the expression of two pro-inflammatory cytokines in patients receiving chemotherapy for cancer. A randomized clinical trial. The Saudi dental journal, 25(4), 141-147.

- Allen, G., Logan, R., Revesz, T., Keefe, D., \& Gue, S. (2018): The prevalence and investigation of risk factors of oral mucositis in a pediatric oncology inpatient population; a prospective study. Journal of pediatric hematology/oncology, 40(1), 15-21.

- Alsoda, F., Al-Shahat, M., Reda, K., Alsawah, Y., Abboud, M., \& Elgendy, E. (2019): Implementation of ventilator bundle for prevention of ventilatorassociated pneumonia in pediatric intensive care unit. Journal of Medicine in Scientific Research, 2(4), 265-274.

- Ames, J. (2011): Evidence to support tooth brushing in critically ill patients. American Journal of Critical Care, 20(3), 242-250.

- Anggraeni, T., Hayati, T., \& Nur'aeni, A. (2020): The Effect of Oral Care Intervention on Oral Health
Status Of Intubated Patients In The Intensive Care UNIT. Belitung Nursing Journal, 6(1), 21-26.

- Blevins, JY (2011): Oral health care for hospitalized children. Pediatric Nursing, Vol. 37 (5), 229-235.

- Da Silva, S., Neto, M., De Aguiar, E., Lopes Jr, E., \& De Carvalho, B. (2010): Impact of sustained neuromuscular blockade on outcome of mechanically ventilated children. Pediatrics International, 52(3), 438-443.

- Dagnew, A., Abraham, A., Beraki, G., Mittler, S., Achila, O., \& Tesfamariam, H. (2020): Do nurses have barriers to quality oral care practice at a generalized hospital care in Asmara, Eritrea? A crosssectional study. BMC oral health, 20(1), 1-11.

- Damascena, L., de Lucena, N., Ribeiro, A., Pereira, L., Lima-Filho, A., \& Valença, G. (2020): Severe oral mucositis in pediatric cancer patients: survival analysis and predictive factors. International journal of environmental research and public health, 17(4), 1235-1242.

- Düzkaya, D. Uysal, G., Bozkurt, G., \& Yakut, T. (2017): The effect of oral care using an oral health care guide on preventing mucositis in pediatric intensive care. Journal of Pediatric Nursing, 36(1), 98-102.

- Gomaa, M., Wahba, Y., \& El-Bayoumi, A. (2017): Pre versus post application of a $0.12 \%$ chlorhexidine based oral hygiene protocol in an Egyptian pediatric intensive care unit: Practice and effects. The Egyptian Journal of Critical Care Medicine, 5(3), 87-91.

- Guimarães, R., de Carvalho, A., Damascena, L., Sampaio, A., Ribeiro, A., de Sousa, A., \& Valença, G. (2021): The incidence of severe oral mucositis and its occurrence sites in pediatric oncologic patients. Medicina Oral, Patología Oral y Cirugía Bucal, 26(3), 299-303

- Gupta, A., Singh, K., \& Saxsena, A. (2016): Role of oral care to prevent VAP in mechanically ventilated Intensive Care Unit patients. Saudi journal of anaesthesia, 10(1), 95-97.

- Harris, J., Harriman, A., Cashavelly, J., \& Cathy Maxwell, N. (2008): Putting evidence into practice $®$ : evidence-based interventions for the management of oral mucositis. Clinical journal of oncology nursing, 12(1), 141-151.

- Kusahara, M., Peterlini, S., \& Pedreira, G. (2012): Oral care with $0.12 \%$ chlorhexidine for the prevention of ventilator-associated pneumonia in critically ill children: randomised, controlled and double blind trial. International journal of nursing studies, 49(11), 1354-1363.

- Kusiak, A., AlicjaJereczek-Fossa, B., Cichońska, D., \& Alterio, D. (2020): Oncological-therapy related oral mucositis as an interdisciplinary problem Literature review. International journal of 
environmental research and public health, 17(7), 2464- 2472.

- Mohammed, H., \& Hassan, M. (2015): Endotracheal tube securements: effectiveness of three techniques among orally intubated patients. Egyptian Journal of Chest Diseases and Tuberculosis, 6(1),4, 183-196.

http://dx.doi.org/10.1016/j.ejcdt.2014.09.006.

- Moustafa, F., Tantawey, M., El-Soussi, H., \& Ramadan, A. (2016): The effect of oral care intervention on the occurrence of ventilatorassociated pneumonia. Gynecol Obstet (Sunnyvale), 6(383), 2161-0932.

- Peres, A., Macpherson, M., Weyant, J., Daly, B., Venturelli, R., Mathur, R., \& Watt, G. (2019): Oral diseases: a global public health challenge. The Lancet, 394(10194), 249-260.

- Saensom, D., Merchant, T., Wara-Aswapati, N., Ruaisungnoen, W., \& Pitiphat, W. (2016): Oral health and ventilator-associated pneumonia among critically ill patients: a prospective study. Oral diseases, 22(7), 709-714.

- Ullman, A Long, D \&Lewis, P (2013): The oral health of critically ill children: an observational cohort study. Journal of Clinical Nursing, 20(1), 3070-3080.

- Yurdanur, D., \& Yagmur, N. (2016): A recent view and evidence-based approach to oral care of intensive care patient. International Journal of Caring Sciences, 9(3), 1177-1185. 